\title{
Pharmacognostic and Phytochemical Evaluation on the Whole Plant of Pavonia odorata Willd.
}

\author{
Neethu Krishnan .S. ${ }^{1}$, Meera Bhaskaran², Mohammed Shihab K K ${ }^{3}$, \\ Fathima Suman $\mathbf{P}^{4}$, Riyama Shirin.V.K \\ 1,3,4,5 Final Year M.Pharm Student, College of Pharmaceutical Science .Gov. Medical College, Kannur, Kerala. \\ ${ }^{2}$ Lecturer, Department of Pharmacognosy, College of Pharmaceutical Science .Gov. Medical College, Kannur,
} Kerala.

Corresponding Author: Neethu Krishnan .S.

\begin{abstract}
Pavonia odorata Willd. belonging to the family Malvaceae is well known for curing a variety of diseases. This study deals with the Pharmacognostical and phytochemical evaluation of whole plant of Pavonia odorata Willd. The plant is widely used as a cooling, diaphoretic, diuretic, and demulcent. It is also prescribed as an astringent and tonic for fever, inflammation and hemorrhage. Pharmacognostical studies include macroscopic, microscopic and physicochemical evaluation of the whole plant. The transverse section of root, stem and leaves were performed. Physicochemical constants showed the values of total ash $(4.45 \%)$, acid insoluble ash $(0.754 \%)$, water soluble ash (6\%), sulphated ash $(6.5 \%)$, nitrated ash (1.65\%), hot extraction $(10.22 \%)$, water soluble extractive $(9.2 \%)$, ethanol soluble extractive $(4.8 \%)$, ether soluble extractive $(1.2 \%)$, loss on drying (25\%), swelling index(1) and mucilage content $(0.25 \%)$ w/w. The preliminary phytochemical screening of the alcoholic extract showed presents of alkaloids, phenolic compounds, steroids, mucilage and flavonoids. The study helps in the development of standard parameters of the plant which help the identification and authentication of the plant.
\end{abstract}

Keywords: Pavonia odorata Willd., pharmacognostical, phytochemical evaluation, Medicinal plant drugs, ethnomedicine

\section{INTRODUCTION}

Medicinal plant drugs have been used as ethnomedicine for the treatment of wide range disease since time immemorial. Herbal drugs played in an important role in maintaining health. Traditionally a large number of medicinal plant parts and their extract are used as raw drugs and they exhibit a wide range of medicinal properties. The local communities and folk healers use these collected drugs for local use as well as ethnomedicine. Some of these drugs are collected in large quantities and used as raw materials by herbal industries. ${ }^{[1]}$ Most of the bioactive phytochemical compounds present in plants produce various physiological activities and may impart a variety of health benefits such as antioxidant, antibacterial, anti-inflammatory or anticancer activity. Herbal medicines have been used in traditional treatments for various human diseases for thousands of years, and they continue to contribute an essential role in providing therapeutic aid for alleviating the ailments of humankind. The therapeutic benefits are obtained from the specific plant compounds; mainly due to the active constituents of the plants. ${ }^{[2]}$

Pavonia odorata Willd, commonly known as Sugandhabala belongs to the family Malvaceae. The genus Pavonia consist of about 70 species. They are erect herb reaches a height of about $45-90 \mathrm{~cm}$. $P$. odorata Willd is widely distributed in Indian subcontinent, Africa, Sri Lanka, Pakistan and Myanmar. ${ }^{[3]}$ In India it is mainly found in deciduous forest up to an altitude of $1000 \mathrm{~m}$. Also found in the 
warmer parts like Andhra Pradesh, Bihar, Karnataka, Kerala, Orissa, Maharashtra Punjab, Rajasthan, Tamilnadu, Uttar Pradesh and West Bengal. Pavonia odorata Willd (Malvaceae) is an indigenous medicinal plant of India that is frequently used in Ayurvedic system of medicine as a cooling, diaphoretic, diuretic, and demulcent .In combination with other plant drugs, it is prescribed as an astringent, tonic for fever, inflammation and hemorrhage. It has been reported for anti- inflammatory, anti-microbial, anticancer, antioxidant, antifungal, antibacterial, antidiabetic, antiulcer, antitumor immunomodulatory, and cardiovascular activity. ${ }^{[4]}$

\section{MATERIALS AND METHODS Sample collection, identification and preparation}

The whole plants of Pavonia odorata Wiild were collected from natural habitat in and around Wayanad district, Kerala on January 2020. The plant was identified and authenticated by Dr.P.Sreeja, Dept. of Botany and Research Centre Sir Syed College Talipramba, Kannur Kerala, India. The whole plant were washed in clean water and shade dried. After drying, it was ground to yield fine powder for further analyses.

\section{Preliminary Pharmacognostical study}

Macroscopy-The various parts like leaves, stem, and root of Pavonia odorata Willd was studied individually for its morphological characters such as color, odor, taste, shape, size, etc.

Microscopy-The transverse section of leaf, stem and root of the plant were taken and photographs were done. The parts were properly mounted and stained according to the standard procedure. The microscopic features of the powder of whole plant were also done. For examining the cell structures in powder form, the powder was treated with chloral hydrate and stained with phluroglucinol and $\mathrm{Hcl}$, mounted with glycerin and observed under Scanning Electron Microscope.

\section{Physico-chemical analysis}

Physicochemical parameters like moisture content, total ash, water insoluble ash, acid insoluble ash, sulphated ash, nitrated ash, volatile oil content, alcohol soluble extractive ,ether soluble extractive, water soluble extractive ,mucilage content, foaming index and swelling index were determined according to the methods cited in the Ayurvedic Pharmacopoeia of India. ${ }^{[5]}$ (Table 1)

\section{Preliminary Phytochemical Analysis}

For preliminary phytochemical tests, $35 \mathrm{~g}$ powdered material was successively extracted using Soxhlet apparatus with petroleum ether, chloroform, ethylacetate, methanol and water. The presence of different phytoconstituents viz., alkaloids, carbohydrates, proteins, amino acid. fat and oils, terpenoids, steroids, saponins, tannins, flavonoids, phenol, anthraquinones and glycosides were determined using standard procedure. ${ }^{[6-7]}$ (Table 2)

\section{RESULTS AND DISCUSSION \\ Pharmacognostical study \\ Pavonia odorata Willd \\ Kingdom - Plantae \\ Order - Malvales \\ Family - Malvaceae \\ Sub family - Malvoideae \\ Tribe - Hibisceae \\ Genus - Pavonia \\ Species - Pavonia odorata}

\section{Macroscopic Evaluation}

The characters recorded are described below.

Leaf - They are 3-5lobed, ovate in shape. Size $2.5-7.5 \mathrm{~cm}$. The lower ones are entire, stellate hairy on both surfaces, lower petioles are usually longer than the blades Mild aromatic and bitter in taste.

Root - they are of diverse sizes, surface are rough and brown. Cork is peelable, musk like aromatic odour.

Stem - they are viscously covered with pubescence and short hairs .Odourless and slightly bitter in taste. 
Neethu Krishnan .S. et.al. Pharmacognostic and phytochemical evaluation on the whole plant of pavonia odorata willd.

\section{Microscopy \\ Root}

A transverse section of the root shows a thin zone composed of phellem, phellogen and phelloderm. The cork is composed of 6to 12 layered, thin walled, irregular in shape, filled with brown color cell content, rich in starch and druses. Cortex collenchymatous cells are circular to oval with thick intercellular spaces. Cortex consists of abundant agglomerated starch grains and druses. A few raphides are also present. Discontinuous layer of sclerenchymatous cells forming the pericyclic fiber. Vascular bundles without a bundle cap or limiting layer radial with xylem and phloem alternating with each other, cambium inconspicuous. Many bundles embedded in the parenchymatous tissue, xylem interspersed with uniseriate and triseriate medullary rays. The pith is absent.

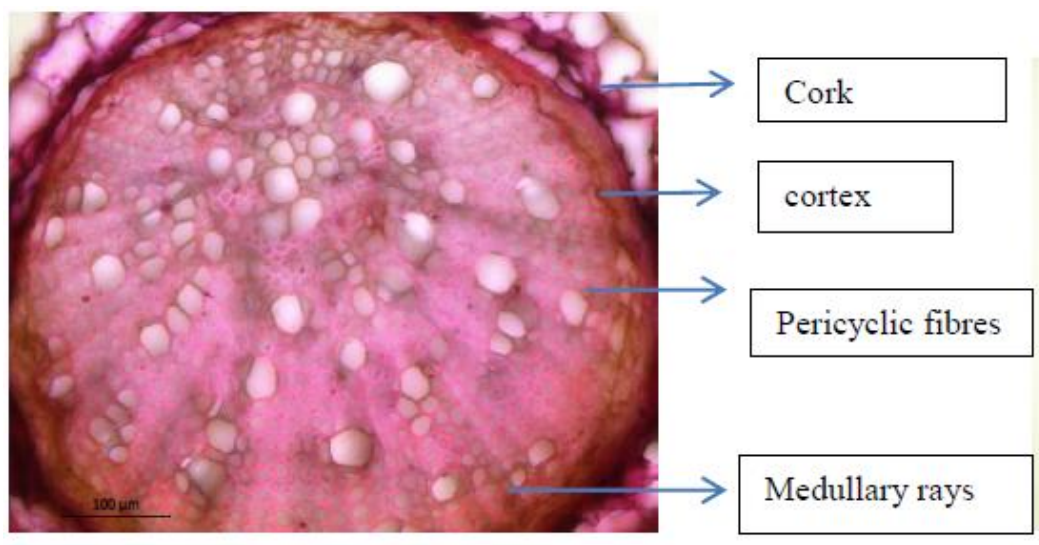

Figure 1 T.S. of root

\section{Stem}

The epidermis is composed of a single layer of rectangular closely-packed cells. The unicellular non-glandular trichomes occur on stem as epidermal outgrowths. Pink color indicates the presence of lignified cells. Lignified fibers are present in groups. Vascular bundle

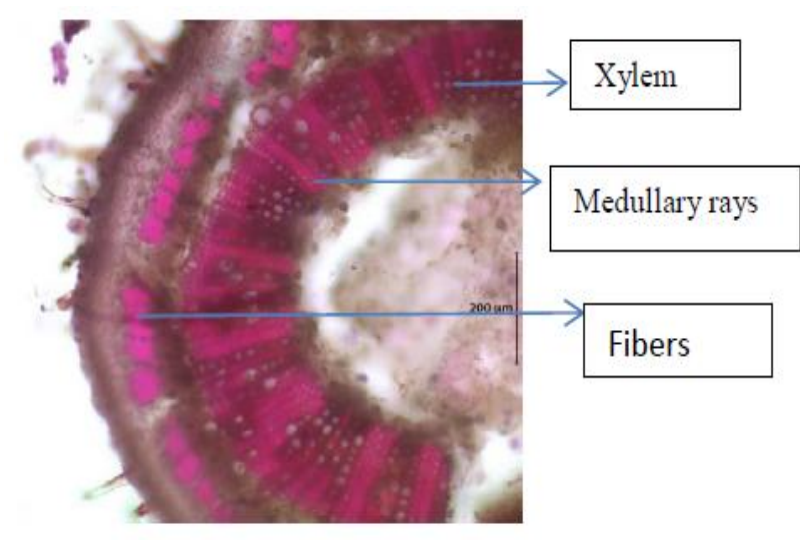

Figure 3 T.S. of stem

\section{Leaf}

The section of leaf is bilateral .The upper and lower epidermis is composed of a single layer of rectangular and tightly- consists of xylem and phloem. Xylem is seen distant as large vessels, covered with phloem cells and appear as concentric vascular bundle arrangement. The medullary rays are alternately arranged with vascular bundle. Above the vascular bundle cambium is seen. Central position is pith filled with parenchymatous cells.

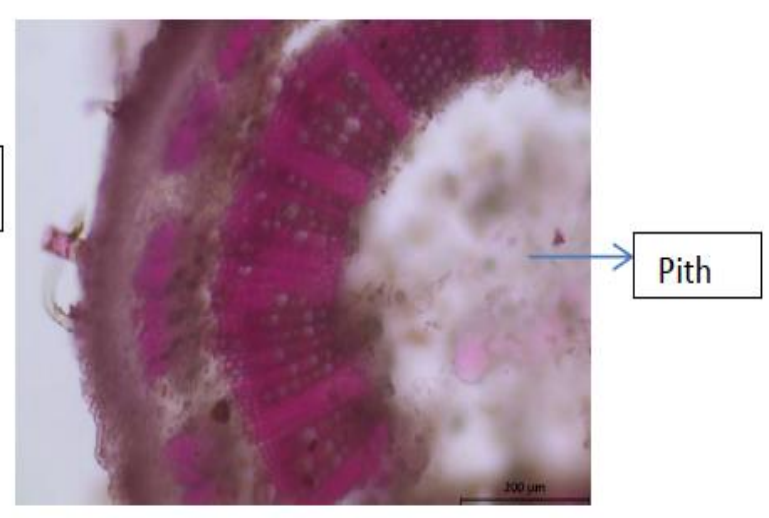

Figure 4 T.S. of stem

packed cells. Stomata are present in upper and lower epidermis. Due to the abundant presence of trichomes they are not distant. The epidermis of the cells is covered with 
thick cuticle. The mesophyll consists of tightly arranged palliside cells with lower lying spongy parenchyma. The midrib consists of collenchyma lying below the upper and above the lower epidermal layer. The central portion consists of distant

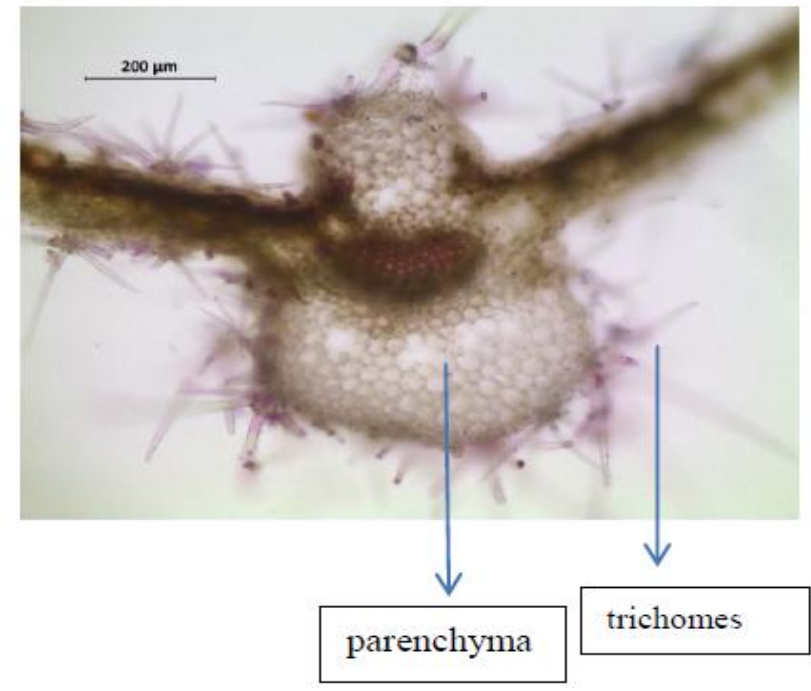

Figure 5 T.S. of leaf

The above parameters help in identifying the species and to establish the authenticity of this plant and can possibly help to differentiate the drug from its other adulterants.

\section{Powder characteristics}

Colour-Light Brown

Odour - Aromatic

Taste - Bitter

Touch - Rough, Coarse

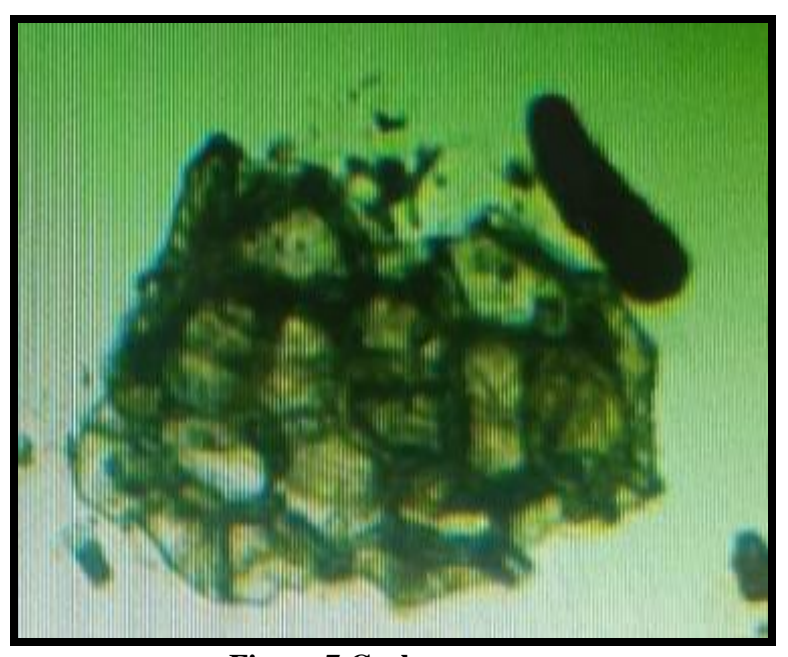

Figure 7 Cork vascular bundle with the large xylem surrounded by the phloem cells. Parenchyma cells are filled in the midrib region. Trichomes are unicellular multicellular.

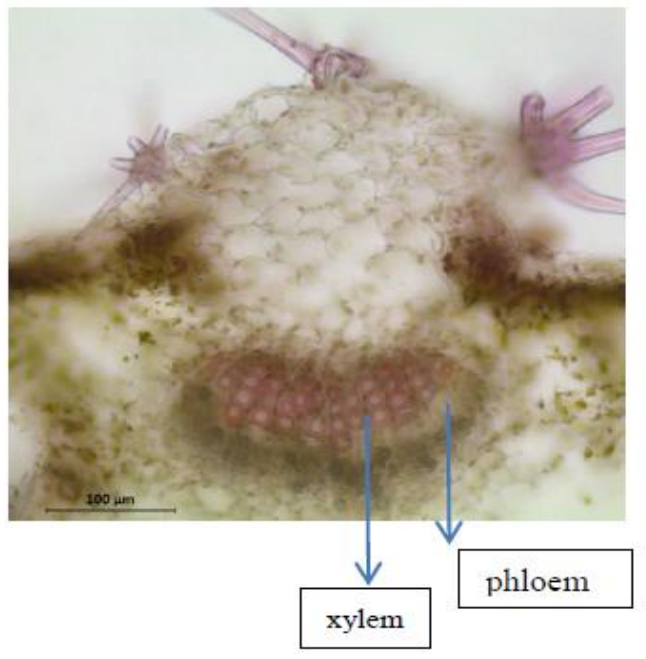

Figure 6 T.S. of leaf

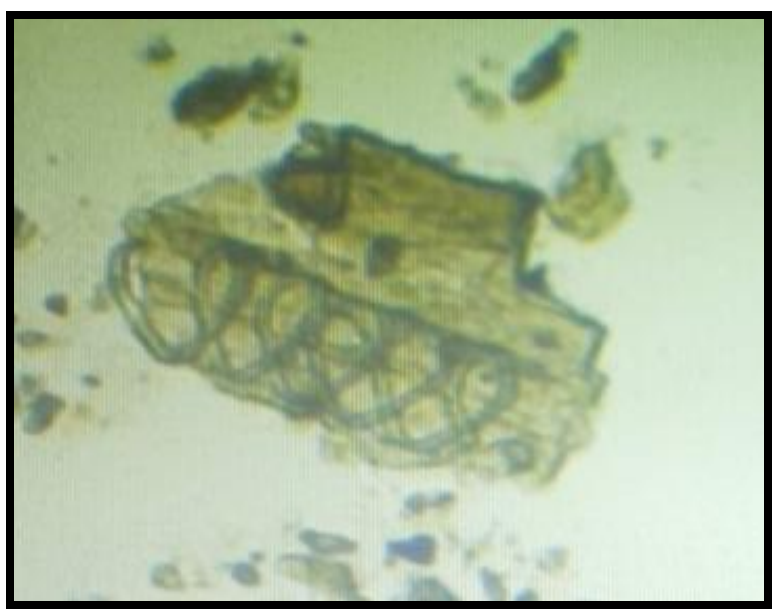

Figure 8 Spiral xylem vessel

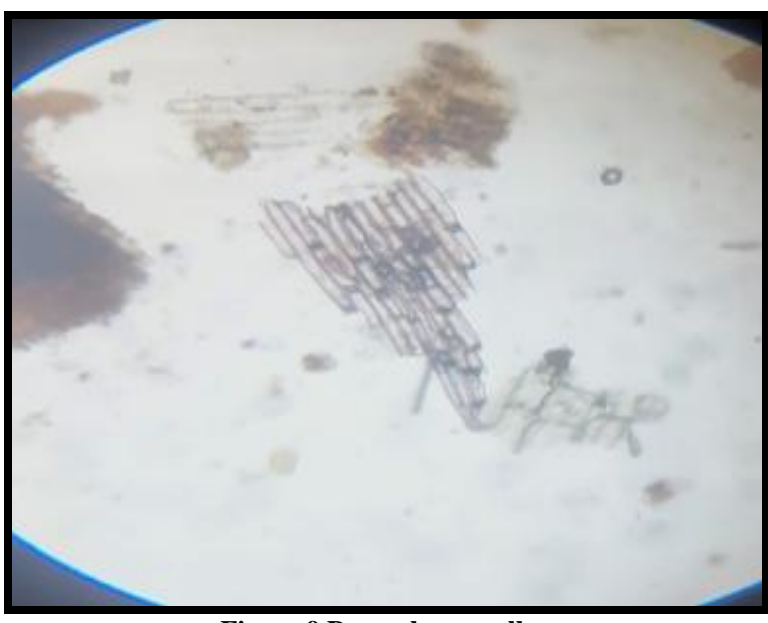

Figure 9 Parenchyma cells 


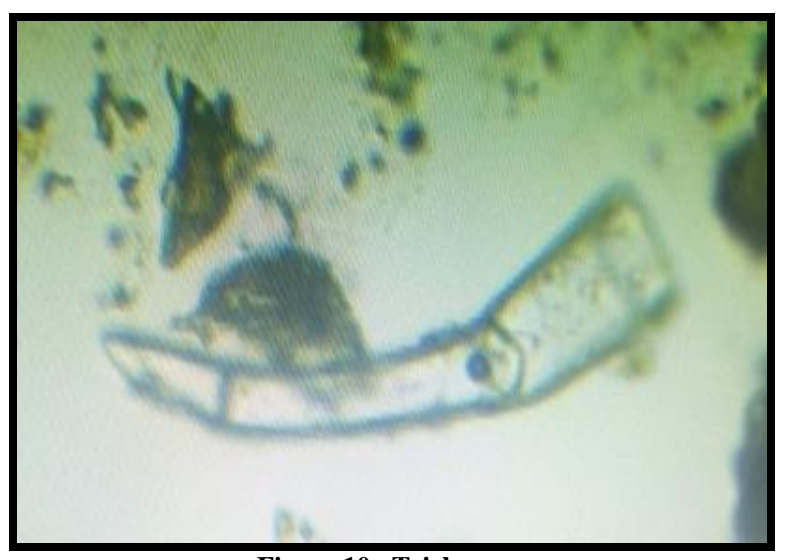

Figure 10 Trichome

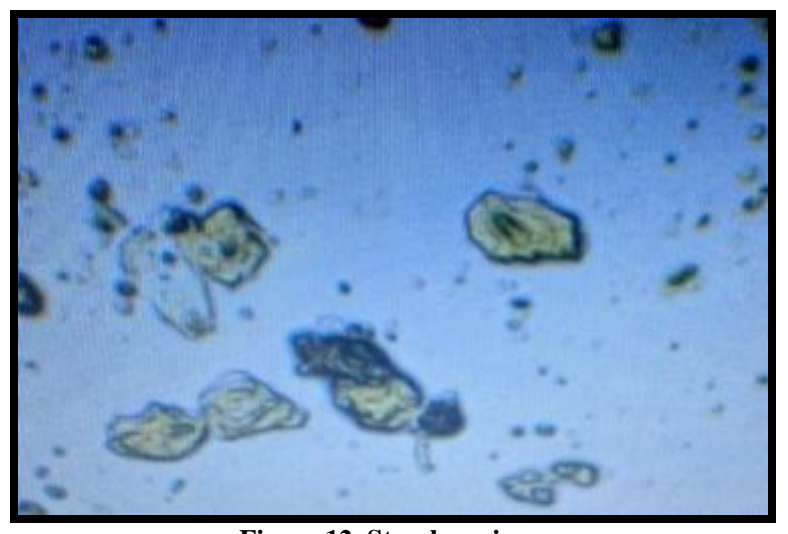

Figure 12 Starch grains

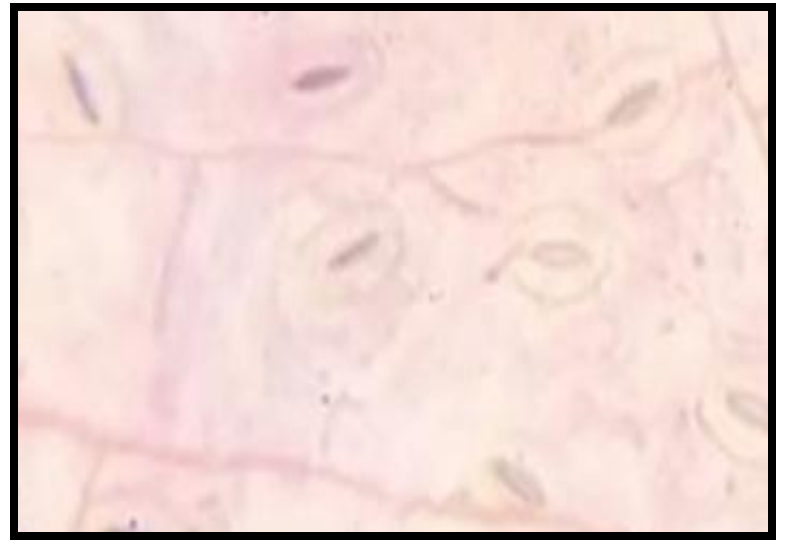

Figure 11 Stomata

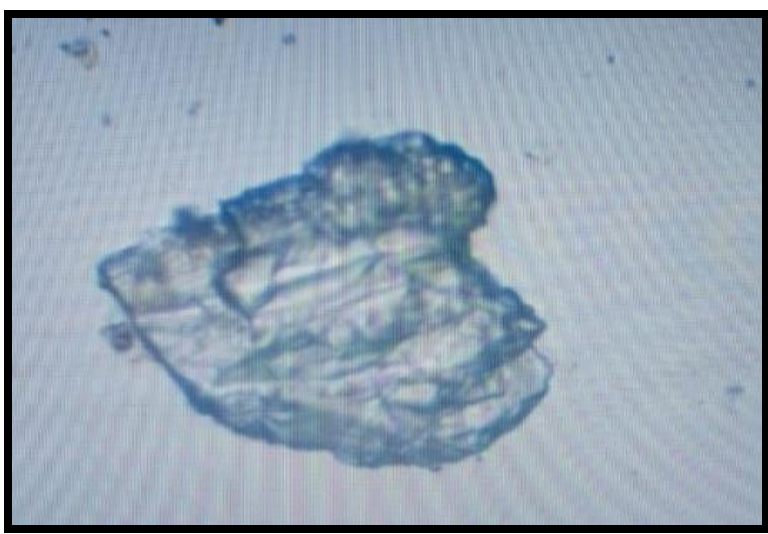

Figure 13 Calcium oxalate

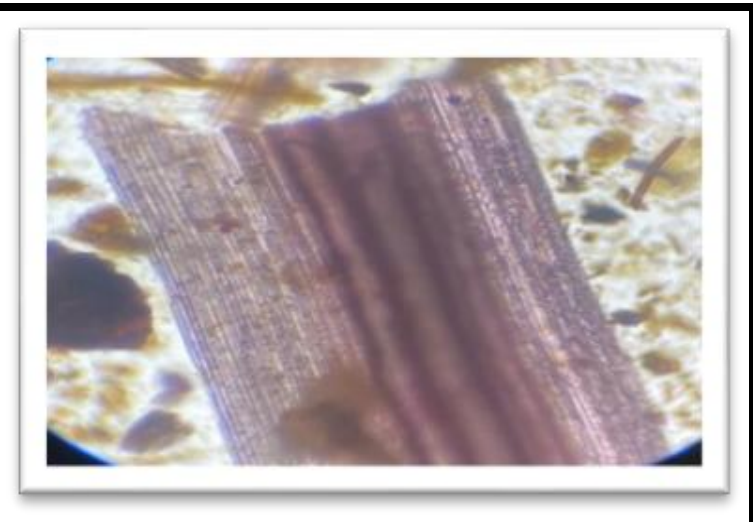

Figure 14 Wood elements

\section{Physicochemical Parameters}

\begin{tabular}{|l|l|}
\hline Physicochemical Parameters & Results \\
\hline Ash value & \\
\hline (a) Total ash & $4.45 \%$ \\
\hline (b) Acid insoluble ash & $0.754 \%$ \\
\hline (c) Water soluble ash & $6 \%$ \\
\hline (d) Sulphated ash & $6.5 \%$ \\
\hline (e) Nitrated ash & $1.65 \%$ \\
\hline Extractive values & \\
\hline (a) Hot extraction & $10.22 \%$ \\
\hline (b) Water soluble extractive & $9.2 \%$ \\
\hline (c) Ethanol soluble extractive & $4.8 \%$ \\
\hline (d) Ether soluble extractive & $1.2 \%$ \\
\hline Loss on drying & $25 \%$ \\
\hline Foaming index & Nil \\
\hline Swelling index & 1 \\
\hline Mucilage content & $0.25 \%$ \\
\hline
\end{tabular}

Physicochemical parameters are important parameters in detecting adulteration and are adopted to confirm the purity and quality of drug. Ash values are particularly important parameter as it shows the presence and absence of foreign matters like metallic salts or silica etc.

\section{Phytochemical Evaluation}

Phytochemical screening showed the presence of alkaloids, flavonoids, steroids, mucilage, carbohydrates and phenolic compounds. 
Neethu Krishnan .S. et.al. Pharmacognostic and phytochemical evaluation on the whole plant of pavonia odorata willd.

Table 2

\begin{tabular}{|l|l|c|c|c|c|c|}
\hline SN & PHYTOCHEMICALS & $\begin{array}{l}\text { PETROLEUM } \\
\text { ETHER }\end{array}$ & CHLOROFORM & $\begin{array}{l}\text { ETHYL } \\
\text { ACCETATE }\end{array}$ & METHANOL & WATER \\
\hline 1 & ALKALOIDS & - & + & - & - & - \\
\hline 2 & CARBOHYDRAYES & - & - & - & - & + \\
\hline 3 & SAPONINS & - & - & - & - & - \\
\hline 4 & FLAVANOIDS & - & - & - & + & + \\
\hline 5 & STEROIDS & + & - & - & - & - \\
\hline 6 & MUCILAGE & - & - & - & + & + \\
\hline 7 & FAT \& OILS & + & - & - & - & - \\
\hline 8 & PHENOLIC COMPOUNDS & - & - & - & + & + \\
\hline 9 & GLYCOSIDES & - & - & - & - & - \\
\hline
\end{tabular}

\section{DISCUSSION}

The present work deals with the Pharmacognostical and phytochemical study of the whole plant of the Pavonia odorata Willd. The pharmacognostic parameters can be used to differentiate closely related plant species or varieties with similar constituents or pharmacological activities. Microscopic analysis carried out on plant samples in order to establish appropriate data that can be used for identifying crude drugs. Powder study of whole plant revealed the presence of covering trichomes, spiral xylem vessels, fibers, cork cells, stomata, and starch grains. Phytochemical analysis showed the presence of important classes of phytoconstituents like alkaloids, mucilage, flavonoids, phenolic compound and steroids. This indicates that the plant can be useful for treating different diseases because the therapeutic activity of a plant is due to the presence of particular class of compounds. The present work can be useful in standardizing the herbal formulations containing Pavonia odorata.

\section{CONCLUSION}

It is concluded that the above parameters are very useful for the identification and authentication of the species. The results of the present study will also be helpful in preparation of monograph.

\section{ACKNOWLEDGEMENT}

All authors have no conflict of interest. This research did not receive any specific grant from any funding agency.

Conflict of Interest: None

\section{Source of Funding: None}

Ethical Approval: Approved

\section{REFERENCES}

1. Uniyal S.K, K. N. Singh, P. Jamwal and B. Lal, (2006)Traditional use of medicinal plants among the tribal communities of chotta bhangal, western Himalayan J. Ethnobiol. Ethnomed, 2: 1- 4.

2. Dorman ,HJ and Deans, SG(2000). Antimicrobial agents from plants: antibacterial activity of plat volatile oils .J.Applmicrobial.88:308-316.

3. Singhai, A., Singour, P.K., Garg, G., Pawar, R.S. and Patil, U.K. (2009). In Vitro Study on Pavonia odorata (Roots) For Anthelmintic Activity. Res J Pharmacol Pharmacodynamics 1:82-84.

4. Kashima, Y., Nakaya, S. and Miyazawa, M. (2014). Volatile composition and sensory properties of Indian herbal medicinePavonia odorata used in Ayurveda. J Oleo Sci 63:149-58.

5. Anonymous. The Ayurvedic Pharmacopoeia of India. Ministry of Health and Family Welfare, Department of Ism and H, Govt of India, New Delhi; 2001. Part-I. Vol III: PP169-171.

6. Khandelwal K.R,Pratical Pharmacognosy techniques and experiments .Nirali Prakashan, $8^{\text {th }}$ Edition (2001).

7. Kokate CK.,In ,Pratical pharmacognosy .Vallabha Prakashan,New Delhi,107-103.

How to cite this article: Neethu Krishnan .S., Bhaskaran M, Mohammed Shihab K K et.al. Pharmacognostic and phytochemical evaluation on the whole plant of pavonia odorata willd. International Journal of Research and Review. 2021; 8(8): 359-364. DOI: https://doi.org/10. 52403/ijrr.20210849 